\title{
Morfogênese da grama-tapete em resposta à adubação com dejeto líquido de suínos
}

\author{
Morphogenesis of carpet grass in response to pig slurry fertilization
}

\author{
Magdalena Reschke Lajús Travi ${ }^{{ }^{*}}$ Simone Meredith Scheffer-Basso ${ }^{\mathrm{II}}$ \\ Pedro Alexandre Varella Escosteguy ${ }^{\mathrm{II}}$ Karen Döering Brustolin ${ }^{\mathrm{I}}$ Valdirene Zabot $^{\mathrm{I}}$ \\ Mario Miranda ${ }^{\text {III }}$
}

RESUMO

Este trabalho teve como objetivo avaliar a morfogênese da grama-tapete (Axonopus affinis) adubada durante dois anos com dejeto líquido de suínos (DLS). Na média de dois anos, foram aplicados 0, 51, 102, 153, 204 e 255m de DLS ha-1, calculados para prover 0, 100, 200, 300, 400 e $500 \mathrm{~kg}$ de $\mathrm{N} / \mathrm{ha} /$ ano, respetivamente. A morfogênese foi avaliada na primavera e verão de 2008-2009 e 2009-2010, considerando-se como temperatura basal $10^{\circ} \mathrm{C}$ para cálculo da soma térmica no intervalo entre as amostragens. Houve aumento linear no número de perfilhos, taxa de alongamento de perfilhos, taxa de expansão foliar e índice de área foliar em função das doses de DLS. Não houve efeito da adubação na taxa de alongamento de pseudocolmo $\left(0,004 \mathrm{~cm} \mathrm{GD}^{-1}\right)$, taxa de aparecimento foliar $(0,004$ folha perfilho-1 $\left.G D^{-1}\right)$ e filocrono (274GD).

Palavras-chave: Axonopus affinis Chase, adubação orgânica, filocrono, perfilhos, taxa de expansão foliar.

\section{ABSTRACT}

This study aimed to evaluate the morphogenesis of carpet grass fertilized for two years with pig slurry (PS). On the average of two years were applied 0, 51, 102, 153, 204 and $255 \mathrm{~m}^{3}$ of PS ha-1, calculated to provide $0,100,200,300,400$ and $500 \mathrm{~kg}$ of $N$ ha $^{-1}$ year ${ }^{-1}$, respectively. The morphogenesis was evaluated in the spring and summer of 2008-2009 and 2009-2010, considering $10^{\circ} \mathrm{C}$ as threshold temperature to evaluate the thermal sum in degree-days $(D D)$ between the samplings. The fertilization linearly increased the tiller number, tiller elongation rate, leaf elongation rate and leaf area index. There was no effect of the fertilization on pseudoculm elongation rate $\left(0.004 \mathrm{~cm} D D^{-1}\right)$, leaf appearance rate (0.004 leaf tiller $\left.{ }^{-1} D^{-1}\right)$ and phyllochron (274DD).

Key words: Axonopus affinis Chase, leaf elongation rate, organic fertilization, phyllochron, tillers.

\section{INTRODUÇÃO}

Entre as mais importantes espécies das pastagens naturais do sul do Brasil, destacase a grama-tapete (Axonopus affinis Chase), que apresenta boa resistência ao frio, pisoteio animal, agressividade e produção de matéria seca. Juntamente com a grama-forquilha (Paspalum notatum Flügge), são as principais gramíneas do estrato inferior das pastagens naturais (BOLDRINI, 2006). No entanto, seu potencial forrageiro tem sido subestimado, em virtude da limitação de estudos sobre sua resposta a práticas de manejo, tais como a adubação nitrogenada. Suas raízes são superficiais, o que a torna particularmente sensível à seca, mas seu principal benefício é a tolerância a solos com baixa fertilidade, onde outras espécies, mais exigentes, não persistem (HENSKENS, 1997).

Considerando a importância da gramatapete nos campos do sul do Brasil, vários fatores merecem ser investigados, a fim de valorizar esse germoplasma e subsidiar práticas de manejo. Entre os principais fatores a serem investigados para o incremento da produtividade desta gramínea, está a resposta à adubação nitrogenada, principal ação para o aumento da produtividade das pastagens. Esse elemento atua, principalmente, no afilhamento e expansão foliar (CRUZ \& BOVAL, 2000), mas há variações genotípicas, o que evidencia a importância no desenvolvimento de estudos com as principais espécies presentes nas pastagens naturais.

\footnotetext{
IPrograma de Pós-graduação em Agronomia, Universidade de Passo Fundo (UPF), 99052-900, Passo Fundo, RS, Brasil. E-mail: magtravi@hotmail.com. *Autor para correspondência.

"UPF, Passo Fundo, RS, Brasil.

IIIEmpresa de Pesquisa Agropecuária e Extensão Rural (Epagri), Chapecó, SC, Brasil. Recebido 28.01.13 Aprovado 10.08.13 Devolvido pelo autor 06.01.14 CR-2013-0108.R1
} 
Dentre as fontes de nitrogênio, destacase o dejeto líquido de suínos (DLS), cuja utilização em pastagens é uma alternativa para sua reciclagem. $\mathrm{O}$ aumento da produtividade de pastagem natural (SCHEFFER-BASSO et al., 2008) e da gramamissioneira-gigante (Axonopus jesuiticus (Araújo) Valls X Axonopus scoparius (Flüggé) Kuhlm) (MIRANDA et al., 2012) adubadas com DLS indicam seu valor como fertilizante nitrogenado alternativo. Contudo, estudos sobre o efeito do DLS na morfogênese das gramíneas ainda não está esclarecido. Estudos dessa natureza têm sido frequentemente realizados com adubação nitrogenada mineral (MORAIS et al., 2006; SOUSA et al., 2010), que apontam o efeito positivo do $\mathrm{N}$, principalmente, na taxa de expansão foliar, afilhamento e índice de área foliar. Este trabalho teve como objetivo avaliar a morfogênese da grama-tapete em função de doses de DLS.

\section{MATERIAL E MÉTODOS}

O estudo foi conduzido, entre setembro de 2008 e outubro de 2010, em Chapecó, Santa Catarina, a $679 \mathrm{~m}$ de altitude, $27^{\circ} 07^{\prime} \mathrm{S}$ e $52^{\circ} 37^{\prime} \mathrm{W}$, em Latossolo vermelho distrófico. O clima é subtropical Cfa e as temperaturas médias e precipitações mensais foram obtidas na Estação Experimental da Epagri Chapecó, onde o trabalho foi desenvolvido (Figura 1). A pastagem recebeu seis doses de DLS, calculadas para disponibilizar 0 (testemunha), 100, 200, 300, 400 e $500 \mathrm{~kg}$ de $\mathrm{N} \mathrm{ha}^{-1} \mathrm{ano}^{-1}$. De acordo com o teor de $\mathrm{N}$ total do DLS, isso representou na média dos anos aplicados 0, 51, 102, 152, 204 e
$255 \mathrm{~m}^{3}$ ha $^{-1}$ ano $^{-1}$. O delineamento foi em blocos casualizados com cinco repetições, cujas unidades experimentais mediram $6 \mathrm{mx} 5 \mathrm{~m}$. As doses do DLS foram aplicadas de forma fracionada, em quatro aplicações anuais, imediatamente após os cortes da pastagem e em superfície. Como esse fertilizante contém, normalmente, elevadas concentrações de P e K, nos dois anos de avaliação, foram distribuídos, superficialmente, no tratamento testemunha, $220 \mathrm{~kg}$ ha $^{-1}$ ano $^{-1}$ de superfosfato triplo, em uma só vez, no início da primavera, e $155 \mathrm{~kg} \mathrm{ha}^{-1}$ de cloreto de potássio, 2/3 no início da primavera e 1/3 no verão.

A pastagem foi uniformizada mediante um corte com roçadeira motorizada em setembro/2008, com posterior retirada do material da superfície das parcelas, quando recebeu a primeira aplicação do DLS. Os cortes posteriores foram realizados da mesma forma sempre que as parcelas adubadas com a dose intermediária de DLS, equivalente a $300 \mathrm{~kg}$ de $\mathrm{N}$ ha $^{-1}$ ano $^{-1}$, atingiram altura média de $18 \mathrm{~cm}$, deixandose um resíduo médio de $8 \mathrm{~cm}$ de altura. As avaliações morfogenéticas foram realizadas semanalmente entre 8 e 23 de dezembro/2008 (primavera/2008), 29 de dezembro/2008 e 26 de janeiro/2009 (verão/2009), 26 de outubro/2009 e 2 de dezembro/2009 (primavera/2009) e entre 22 de fevereiro/2010 e 19 de março/2010 (verão/2010).

No dia seguinte a cada corte, foram marcados cinco perfilhos, de mesmo padrão vegetativo, presentes em uma transecta de um metro no centro de cada parcela, espaçados $20 \mathrm{~cm}$ entre si, o que totalizou 25 perfilhos por tratamento/época de amostragem. Semanalmente, foram realizadas as seguintes avaliações: a) comprimento das lâminas

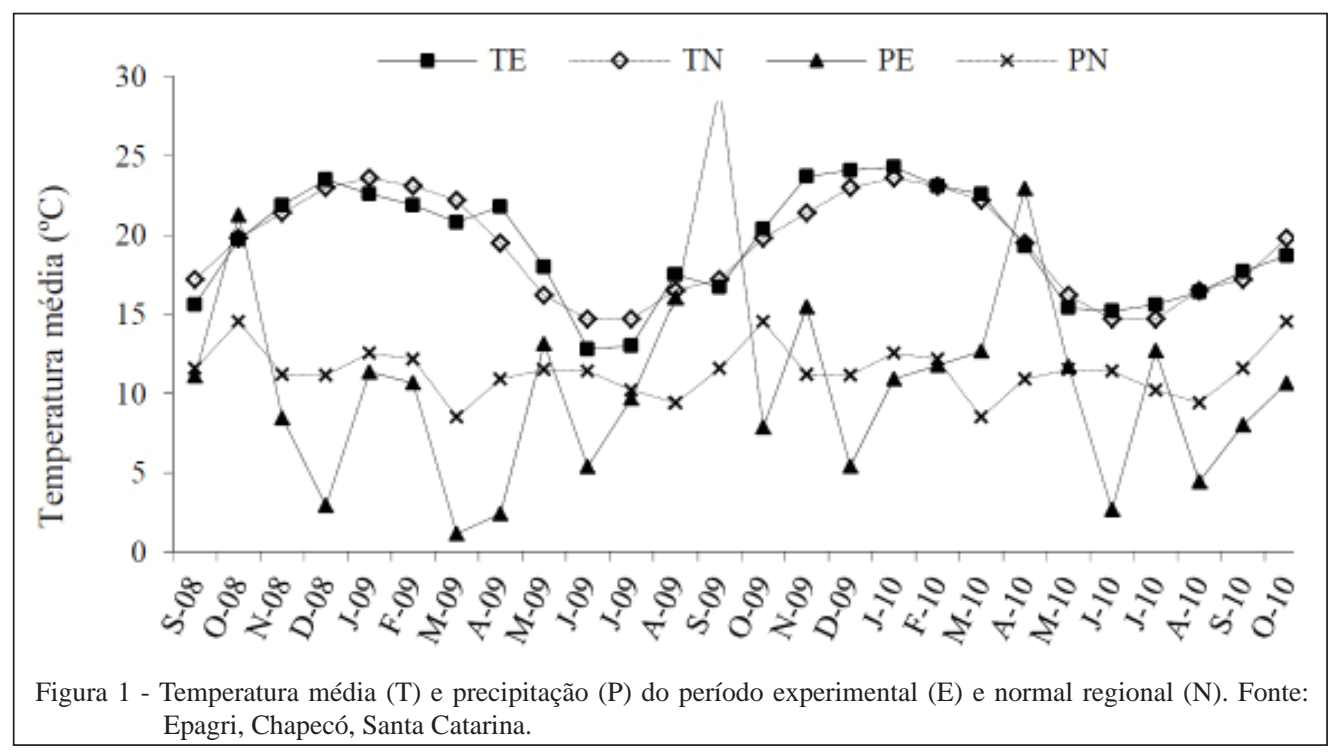

Ciência Rural, v.44, n.3, mar, 2014. 
foliares verdes/perfilho, total e parcialmente expandidas; b) número e classificação das folhas: as folhas foram classificadas em totalmente expandidas (quando a lígula estava exposta), em expansão e em senescência (mais da metade da lâmina clorótica); c) altura dos perfilhos, medida entre a sua base e o ápice da última lâmina foliar expandida; d) altura do pseudocolmo, considerada como sendo a distância entre a base e a lígula da última folha completamente expandida. A partir dos atributos diretamente avaliados, foram calculadas as seguintes variáveis morfogenéticas: a) comprimento total de lâmina foliar (CFL): obtido pelo somatório das lâminas foliares verdes de cada perfilho; b) taxa de expansão foliar (TAF): avaliada pela diferença entre o comprimento final e inicial de lâmina foliar/perfilho, dividido pelo número de dias e de graus-dia entre duas avaliações consecutivas; c) taxa de aparecimento foliar (TApF): calculada pela diferença entre o número inicial e final de folhas verdes (NFV), dividido pelo número de dias e de graus-dia entre duas avaliações consecutivas; d) taxa de alongamento de perfilhos (TAlP): avaliada pela diferença média entre a medida da base de cada perfilho até o ápice da última lâmina foliar expandida; e) filocrono: determinado por meio do inverso da TApF (1/TApF); f) duração de vida da folha (DVF): obtida por meio da multiplicação do filocrono pelo número de folhas verdes completamente expandidas (FVCE) em cada período; g) número de perfilhos e índice de área foliar (IAF): foram mensurados mediante a colheita do material vegetal presente em uma área amostral de 0,50mx0,50m, considerandose altura de resíduo médio de 7-8cm. Assim, foram contados apenas os perfilhos com comprimento acima desse valor. A área foliar foi obtida mediante a mensuração da área das folhas verdes presentes nessa amostra, em planímetro eletrônico. A partir disso, foi calculado o IAF. As variáveis foram calculadas para cada perfilho individualmente e, posteriormente, foi obtida a média para cada parcela. O tempo decorrido entre as avaliações foi estimado em dias e em grausdia, considerando-se temperatura basal de $10^{\circ} \mathrm{C}$ (COSTA et al., 2011).

Os dados foram submetidos à análise de variância no modelo de medida repetida no tempo, com posterior regressão das variáveis-resposta em função de doses de DLS e com a comparação de épocas pelo teste de Tukey a 5\% de probabilidade de erro. A análise estatística foi realizada com o programa SISVAR ${ }^{\circledR}$ versão 5.1.

\section{RESULTADOS E DISCUSSÃO}

A adubação aumentou linearmente o número de perfilhos, independentemente da estação de crescimento (Figura 2). A resposta positiva dessa variável à adubação nitrogenada mineral tem sido verificada em diversos estudos, como foi verificado em braquiária (Brachiaria decumbens Stapf.), adubada com até $300 \mathrm{~kg}_{\text {de }} \mathrm{N} \mathrm{ha}^{-1}$ (MORAIS et al., 2006), e em capim-tangola (B. radicans (Rendle) Schweickt $x$ B. mutica (Forsk.) Stapf)), com até $600 \mathrm{~kg}$ de N/ha (SOUSA et al., 2010). No entanto, poucos estudos têm sido desenvolvidos com nitrogênio aplicado na forma orgânica, o que valoriza os dados aqui apresentados, especialmente em se tratando de grama-tapete, importante espécie do sul do Brasil e ainda pouco estudada. BELLON et al. (2009) observaram resposta quadrática de perfilhos de milheto (Pennisetum glaucum (L.) Leeke), cultivado em vasos, à adubação com dejeto líquido de suínos. Os autores verificaram redução no número de perfilhos a partir da dose de com

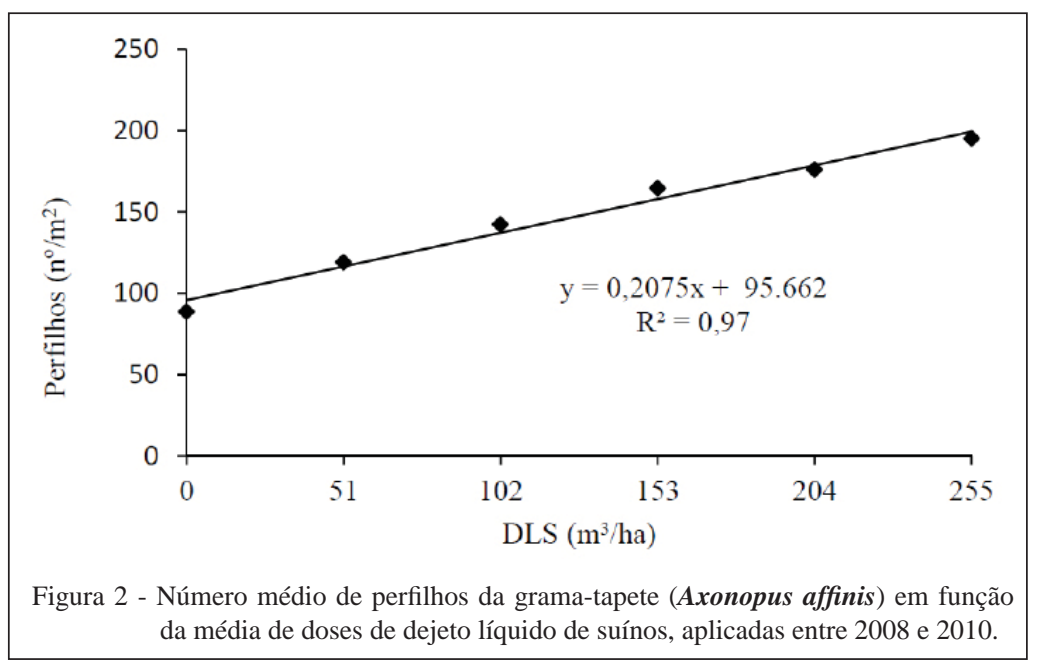

Ciência Rural, v.44, n.3, mar, 2014. 
$50,9 \mathrm{~m}^{3} /$ ha, equivalente a $67 \mathrm{~kg}$ de $\mathrm{N} \mathrm{ha}^{-1}$, e sugeriram possível carência de outro nutriente.

As taxas de alongamento de perfilhos (TAlP) e de folhas (TAF) da grama-tapete aumentaram linearmente em função das doses de DLS (Figura 3). Tais variáveis são comumente responsivas à adubação nitrogenada, como foi verificado em capim-pojuca (Paspalum atratum Swalen), gramínea nativa perene do centro do Brasil, adubado com nitrato de amônio (ELYAS et al., 2006). Nessa espécie, foi observada resposta quadrática da TAlP, com variação média de $0,126 \mathrm{~cm} \mathrm{dia}{ }^{-1}$. Esse valor foi inferior ao verificado neste estudo, em que a grama-tapete mostrou, em média, $0,277 \mathrm{~cm}$ perfilho ${ }^{-1}$ dia $^{-1}$ ou $0,019 \mathrm{~cm}$ perfilho ${ }^{-1} \mathrm{GD}^{-1}$, indicando diferenças genotípicas e, possivelmente, ambientais.

A aplicação da maior dose do DLS promoveu acréscimo de 65,6\% na TAF em relação à testemunha (Figura 3). Tal medida correlacionase positivamente com o rendimento forrageiro, podendo resultar em valores de três a quatro vezes menores num alto nível de deficiência de $\mathrm{N}$, quando comparado a um nível não limitante (GASTAL et al., 1992). MARTUSCELLO et al. (2005), avaliando a TAF do capim-massai, verificaram efeito positivo e linear da adubação nitrogenada mineral na variável, com incremento de 64\% em relação à ausência de adubação nitrogenada. Em capim-caninha (Andropogon lateralis Nees), gramínea nativa do sul do Brasil, BANDINELLI et al. (2003) também observaram resposta crescente na TAF com aplicação de até $200 \mathrm{~kg} \mathrm{ha}^{-1}$ de $\mathrm{N}$ na forma mineral.
A fertilização com DLS incrementou linearmente o IAF da grama-tapete, de 1,74 para 4,57, na média de estação e ano (Figura 4), o que indica a elevada resposta da espécie à adubação nitrogenada. Pode-se atribuir o aumento no IAF à resposta positiva ao DLS no afilhamento e na TAF. NASCIMENTO JÚNIOR et al. (1998), em capimmarandu, e LOPES et al. (2003), em Coastcross-1 (Cynodon dactylon (L.) Pers), também observaram efeito positivo e linear da adubação nitrogenada no IAF dessas gramíneas, confirmando a ação desse nutriente nessa variável. A interceptação da radiação fotossinteticamente ativa é dependente, em grande parte, do IAF, o qual é condicionado pelo balanço entre os processos morfogenéticos e pelo arranjo estrutural deles decorrentes. Dentre os nutrientes, o N participa ativamente desses processos, considerado o principal nutriente para a manutenção da produtividade das gramíneas forrageiras (GASTAL \& LEMAIRE, 1988).

A análise de variância não revelou efeito da adubação na taxa de alongamento do pseudocolmo (TAPC), obtendo-se, na média, $0,0060 \mathrm{~cm}$ dia ou 0,004 $\mathrm{cm} \mathrm{GD}^{-1}$. Em outro tipo de planta, o capimtangola, SOUSA et al. (2010) registraram 0,289cm dia $^{-1}$ com adubação nitrogenada mineral. Essa diferença pode ser atribuída ao perfilho da gramatapete ter vários nós que apresentam alongamento no estádio vegetativo. Em capim-mombaça (Panicum maximum Jacq) e capim-marandu (Brachiaria brizantha (A. Rich.) Stapf), foi observado acréscimo na TAPC em função da adubação mineral nitrogenada com média de 0,2933 e 0,7817cm perfilho-1 dia $^{-1}$, respectivamente (RODRIGUES et al., 2012).

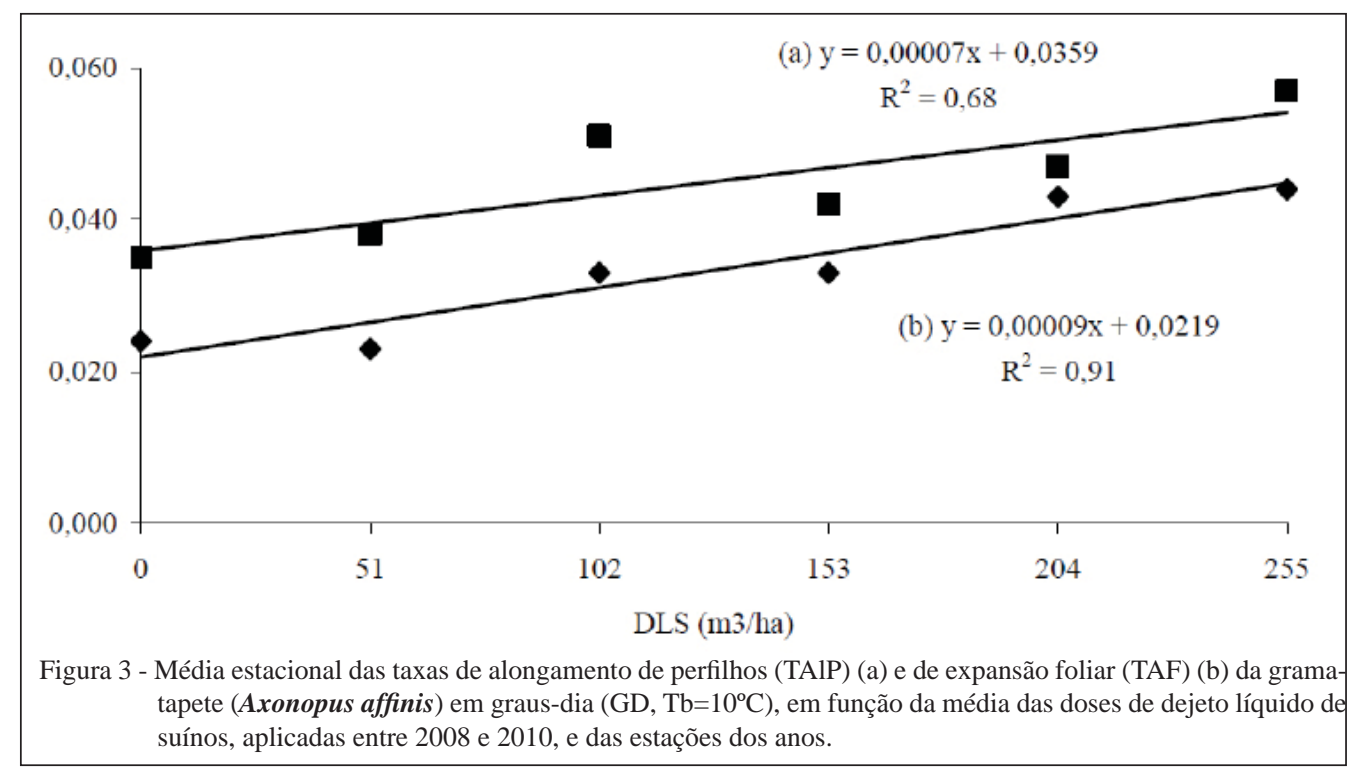

Ciência Rural, v.44, n.3, mar, 2014. 


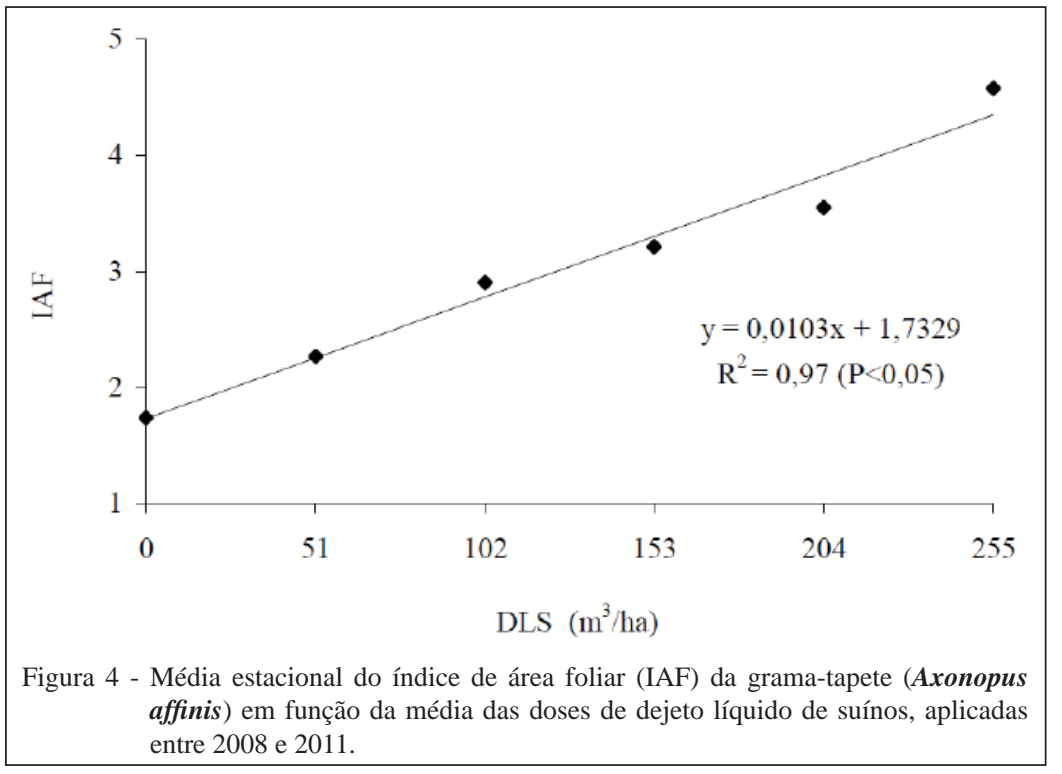

Não foi verificado efeito do DLS na taxa de aparecimento de folhas (TApF), cujo valor médio foi de 0,057 folhas perfilho-1 dia ou 0,004 folhas perfilho-1 $\mathrm{GD}^{-1}$. Em geral, o $\mathrm{N}$ não afeta essa variável, pois, com o avanço dos estádios de desenvolvimento, a planta realoca as prioridades na distribuição de fotoassimilados para os meristemas florais, o que tende a reduzir a formação de novas folhas (SKINNER \& NELSON, 1995). No entanto, há diferenças genotípicas em relação a essa variável, indicando a importância de se ampliar o estudo da morfogênese para as principais espécies forrageiras. OLIVEIRA et al. (2007) relataram que, em condição de alta disponibilidade de $\mathrm{N}$, ocorre aumento do crescimento da planta, com alongamento dos entrenós, empurrando a folha nova para fora da bainha da folha precedente, o que pode causar aumento na taxa de aparecimento foliar. BANDINELLI et al. (2003) verificaram efeito positivo médio do $\mathrm{N}$ em capimcaninha, adubado com $200 \mathrm{~kg}$ de $\mathrm{N} \mathrm{ha}^{-1}$ mineral, de 19,8 folhas perfilho-1 dia $^{-1}$.

Como consequência da ausência de resposta da TApF à adubação, não foi verificado efeito no filocrono da grama-tapete, estimado, neste estudo, em 274GD $\left(\mathrm{Tb}=10^{\circ} \mathrm{C}\right)$. Em capim-caninha, adubado com 200kg de $\mathrm{N} \mathrm{ha}^{-1}$ mineral, BANDINELLI et al. (2003) determinaram filocrono de $200 \mathrm{GD}\left(\mathrm{Tb}=8^{\circ} \mathrm{C}\right)$. EGGERS et al. (2004), em condição natural e sem adubação, quantificaram, para grama-forquilha, filocrono de 156GD $\left(\mathrm{Tb}=8^{\circ} \mathrm{C}\right)$, e, para capim-colade-lagarto (Coelorachis selloana (Hack.) A. Camus), filocrono de 238GD $\left(\mathrm{Tb}=8^{\circ} \mathrm{C}\right)$.
Os resultados deste estudo comprovam a resposta positiva da grama-tapete à adubação nitrogenada na forma de DLS. A elevação do perfilhamento, expansão de folhas e alongamento de perfilhos, bem como do índice de área foliar, indica que o manejo dessa gramínea deve ser flexibilizado em função da adubação nitrogenada, na forma mineral ou orgânica, sugerindo a possibilidade de pastejos mais frequentes quando houver aplicações crescentes de N. Sem um adequado ajuste no manejo do pastejo poderá ocorrer aumento na senescência a acúmulo de material morto na pastagem (GASTAL \& LEMAIRE, 1988). A resposta positiva dessa gramínea indica a possibilidade do aumento da carga e produção animal em áreas de pastagens naturais em que a espécie ocorre, permitindo a valorização do germoplasma nativo do sul do Brasil e, consequentemente, a preservação dessas comunidades vegetais.

\section{CONCLUSÃO}

Doses crescentes de DLS elevam o número de perfilhos, as taxas de expansão foliar e a taxa de alongamento de perfilhos, bem como o índice de área foliar da grama-tapete, sem efeito na taxa de alongamento do pseudocolmo, da duração de vida folha, taxa de aparecimento foliar e filocrono.

\section{AGRADECIMENTOS}

Os autores agradecem ao Conselho Nacional de Desenvolvimento Científico e Tecnológico (CNPq), pelo recurso financeiro disponibilizado mediante o Edital MCT/CNPq/CT-Agro n. 43/2008 - Fontes Alternativas de Nutrientes para a Agricultura 
Brasileira; ao Sr. Bruno Bodanese, pelo fornecimento do DLS; à Epagri, pela cessão da área e infraestrutura, aos seus pesquisadores e equipe técnica, pelo auxílio nas atividades no campo.

\section{REFERÊNCIAS}

BANDINELLI, D.G. et al. Variáveis morfogênicas de Andropogon lateralis Nees submetido a níveis de nitrogênio nas quatro estações do ano. Ciência Rural, v.33, p.71-76, 2003. Disponível em: <http://www.scielo.br/scielo.php?script=sci_artte xt\&pid=S0103-84782003000100011>. Acesso em: 25 mai. 2013. doi: 10.1590/S0103-84782003000100011.

BELLON P.P. et al. Perfilhamento do milheto sob doses crescentes de dejeto líquido de suínos. Synergismus scyentifica, v.4, n.p., 2009. 3p. Disponível em: <http://revistas.utfpr.edu.br/pb/index. php/SysScy/article/viewFile/584/332>. Acesso em: 29 mar. 2012. ISSN: 2316-4689.

BOLDRINI, I. I. Diversidade florística nos campos do Rio Grande do Sul. Os avanços da Botânica no início do século XXI: Morfologia, Fisiologia, Taxonomia, Ecologia e Genética. Porto Alegre. Palotti, v. 1, p. 321-324, 2006.

COSTA N.L. et al. Produtividade de forragem e características morfogênicas e estruturais de Axonopus aureus nos cerrados de Roraima. Amazônia: Ciência \& Desenvolvimento, v.6, p.41-56, 2011. Disponível em: <http://www.basa.com.br/bancoamazonia2/ Revista/edicao_12/n12_produtividade_de_forra.pdf $>$. Acesso em: 30 mai.2012

CRUZ, P.; BOVAL, M. Effect of nitrogen on some morphogenetic traits of temperate and tropical perennial forages. In: LEMAIRE, G. et al. (Eds.). Grassland ecophysiology and grazing ecology. Wallingford, UK: CABI International, 2000. p.151-168. Disponível em: <http://www7.inra.fr/internet/Centres/AntillesGuyane/centre/zoot/publi/publi1999/gee1999_134_r.pdf>. Acesso em: 25 jan. 2013.

EGGERS, L. et al. Phyllochron of Paspalum notatum Fluege and Coelorhachis selloana Hack. Camus in natural pasture. Scientia Agricola, v.61, p.353-357, 2004.

ELYAS, A.C.W. et al. Nitrogênio e saturação por bases no desempenho do capim-pojuca (Paspalum atratum Swalen cv. Pojuca) cultivado em vasos. Ciência e Agrotecnologia, v.30, p.554-561, 2006. Disponível em: <http://www.scielo.br/pdf/ cagro/v30n3/v30n3a23.pdf>. Acesso em: 10 mar. 2013.

GASTAL, F.; LEMAIRE, G. Study of a tall fescue sward grown under nitrogen deficiency conditions. In: MEETING OF THE EUROPEAN GRASSLAND FEDERATION, 12., 1988, Belclare, Irland. Proceedings... Dublin: Irish Grassland Association, 1988. p.323-327. Disponível em: <http://www. scielo.br/scielo.php?script=sci_nlinks\&ref=000159\&pid=S1516 3598200200080000400008\&lng=en>. Acesso em: 25 jun. 2013.

GASTAL, F. et al. A model of the leaf extension of tall fescue in response to nitrogen and temperature. Annals of Botany, v.70, p.437-442, 1992. Disponível em: <http://www.scielo. br/scielo.php?script=sci_nlinks\&ref=000158\&pid=S1516 3598200200080000400007\&lng=en>. Acesso em: 25 mai. 2013.
HENSKENS, F.L.F. The biology and management of Axonopus affinis (Chase) in Australian pastures. Australian Journal of Agriculture Research, v.48, p.1219-1230, 1997. Disponível em: <http://www.publish.csiro.au/paper/A97023.htm>. Acesso em: 10 dez. 2012.

LOPES, R.S. et al. Disponibilidade de matéria seca em pastagens de capim-elefante irrigadas. Ciência e Agrotecnologia, v.27, p.1388-1394, 2003. Disponível em: <http://www.scielo.br/pdf/ cagro/v27n6/25.pdf>. Acesso em: 01 jun. 2013.

MARTUSCELLO, J.A. et al. Características morfogênicas e estruturais do capim-xaraés submetido à adubação nitrogenada e desfolhação. Revista Brasileira de Zootecnia, v.34, p.14751482, 2005. Disponível em: <http://dx.doi.org/10.1590/S151635982005000500007>. Acesso em: 04 dez. 2013.

MIRANDA, M. et al. Dry matter production and nitrogen use efficiency of giant missionary grass in response to pig slurry application. Revista Brasileira de Zootecnia, v.41, p.537543, 2012. Disponível em: <http://dx.doi.org/10.1590/S151635982012000300009>. Acesso em: 30 nov. 2013.

MORAIS, R.V. de. et al. Demografia de perfilhos basilares em pastagem de Brachiaria decumbens adubada com nitrogênio. Revista Brasileira de Zootecnia, v.35, p.380-388, 2006. Disponível em: <http://dx.doi.org/10.1590/S1516-35982006000200007>. Acesso em: 05 dez. 2013.

NASCIMENTO JÚNIOR, D. Ecossistemas de pastagens cultivadas. In: SIMPÓSIO SOBRE MANEJO DA PASTAGEM, 15, 1998, Piracicaba. Anais... Piracicaba: FEALQ, 1998. p.271-296.

OLIVEIRA, A.B. et al. Morfogênese do capim-tanzânia submetido a adubações e intensidades de corte. Revista Brasileira de Zootecnia, v.36, p.1006-1013, 2007. Disponível em: <http:// dx.doi.org/10.1590/S1516-35982007000500004>. Acesso em: 05 dez. 2013.

RODRIGUES, C.S. et al. Grupos funcionais de gramíneas forrageiras tropicais. Revista Brasileira de Zootecnia, v.41, p.1385-1393, 2012. Disponível em: <http://dx.doi.org/10.1590/ S1516-35982012000600010>. Acesso em: 30 nov. 2013.

SCHEFFER-BASSO, S.M. et al. Resposta de pastagens perenes à adubação com chorume suíno: pastagem natural. Revista Brasileira de Zootecnia, v.37, p.221-227, 2008. Disponível em: $<$ http://dx.doi.org/10.1590/S1516-35982008000200007>. Acesso em: 25 mai. 2013

SOUSA, T.V.R. et al. Características morfogênicas e estruturais de capim-tangola sob doses crescentes de nitrogênio. In: REUNIÃO ANUAL DA SOCIEDADE BRASILEIRA DE ZOOTECNIA, 47., 2010, Salvador, Ba. Anais... Salvador: SBZ, 2010. 1 CD-ROM.

SKINNER, R.H.; NELSON, C.J. Elongation of the grass leaf and its relationship to the phyllochron. Crop Science, v.35, p.4-10, 1995. Disponível em: <https://dl.sciencesocieties.org/publications/ cs/abstracts/35/1/CS0350010004?access=0\&view=pdf $>$. Acesso em: 25 mai. 2013. 